\title{
Predictors of Maternal Fetal Attachment among Pregnant Women
}

\author{
${ }^{1}$ Noha Mohamed Mahmoud Hassan, ${ }^{2}$ Fawzia Mohamed Abd Elgwad Hassan \\ ${ }^{1}$ Lecturer of Obstetric and Gynecologic Nursing, \\ ${ }^{2}$ Clinical instructor of Obstetric and Gynecologic Nursing, Faculty of Nursing, Alexandria University, Egypt
}

\begin{abstract}
:
Introduction: Maternal-fetal attachment (MFA) is defined as the affectionate relationship that pregnant women develop for their unborn child. This complex, multi-dimensional relationship is thought to be fundamentally predicts mother and the baby's health status after birth. Thus, it is important to pay more attention into the predictive factors that promoting MFA in childbearing women.

Aim of the study: to find out the predictors of maternal fetal attachment among pregnant women

Materials \& Method: Research design: A descriptive research design was utilized in this study.

Setting: This study was conducted at the outpatient clinic of antenatal unit at El-Shatby Maternity Hospital.

Subjects: convenience sample of 350 pregnant women attending the previously mentioned setting were recruited in the study.

Tools: five tools were used to collect the necessary data: tool (I): Pregnant Women Basic Data Structured Interview Schedule, tool (II): Anxiety Inventory, tool (III): Social Support Structured Interview Schedule and tool (IV): Verbal Maternal-Fetal Attachment (VMFA) structured interview schedule and tool (V): The Pictorial Representation of Attachment Measure (PRAM).

Results: More than three- quarters (81.4\%) of the study subjects had high attachment level compared to only $13.4 \%$ were moderately attached. a statistically significant positive correlation was noticed between subjects' level of overall maternal-fetal attachment and their level of perceived social support $(P=0.001)$

Conclusion: Maternal-fetal attachment level was associated with some predictive factors. Namely, maternal age, gravidity, planned/desired pregnancies, identification of the fetal sex, time of the initial antenatal visit, number of antenatal visits and presence of social support
\end{abstract}

Key terms: maternal fetal attachment, anxiety, social support

\section{Introduction}

Pregnancy is one of the most significant events during woman's life time. It is considered a period with its own tasks, during which the pregnant woman has to adapt to deep physiological, psychological and social changes and development. The expectant mother and her fetus live in symbiosis; she thinks about, imagines and talks to her fetus, communicating with him whatever she feels. The nature of this relationship is often conceptualized by health professionals in term of maternal-fetal attachment (MFA) where every thought, emotion, and feeling that the mother experience is shared and incorporated into the development of her fetus. At the same time her maternal identity is either developed or encumbered. ${ }^{(1)}$

Maternal fetal attachment (MFA) is scientifically defined as "the unique, gradually, reciprocal, multidimensional affectionate relationship that develops between a pregnant woman with her fetus". ${ }^{(2)}$ As early as (1985) Reva Rubin had drawn the attention to MFA. She elaborated that during the first trimester, there is almost no attachment with a fetus because no fetus exists at that time. She becomes only accustomed to and accepting the state of being pregnant. In the second trimester, quickening and hormonal changes increase woman's acceptance of her pregnancy. She focuses on providing a good home for the growing fetus in uterus. Consequently, In the third trimester MFA sprouts and escalates. ${ }^{(3)}$

MFA has several benefits for both the mother and her fetus. It plays an important role in their current as well as postnatal well-being. For the mother, one must not neglect the emotional content of the MFA through the pleasure she gets from interacting with her unborn child. Moreover, MFA is a key element of maternal identity and is necessary for adaptation to motherhood. Furthermore, it notably reinforces the pregnant woman's antenatal healthy behaviors and practices. Specifically, adherence to healthy diets, regular sleep schedules, increased exercise, utilization of needed medical attention, and abstinence from un-prescribed drug use. ${ }^{(4-7)}$

Turning to fetal benefits, literature suggests that MFA affects the development of the fetus's brain and autonomic nervous system. It also influences the child's social development across the lifespan, beyond infancy. This is believed to occur through laying the foundations required for successfully accomplishing the developmental tasks in social and cognitive skills. ${ }^{(8,9)}$ 
MFA is an individual process in its nature and level predicts mother and the baby's health status after birth Thus, it is important to pay more attention into the predictive factors that promoting MFA in childbearing women. These factors are categorized in five main groups: socio- demographic, psychological and social factors.

Socio-demographic factors include: age, level of education and income. Although the transition to motherhood is accepted as stressful for all ages, the relevant literature suggests that the twenties are considered as the ideal age for this transition. Where, they have a greater psychosocial readiness for mothering unlike the teenager mothers who lack the needed knowledge and experiences for effectively parent. They are forced to cope with the added developmental tasks of motherhood beside their uncompleted tasks of adolescence ${ }^{(10)}$. Researches had reported either a positive or inverse or no relation between educational level and MFA. The first group interpreted their results by the notion that education helps mothers to gain information about motherhood and the developing fetus which reflect positively on MFA level. While the second group explained their results by the fact that pregnant women who have higher education level are usually have more responsibilities which may negatively influence the interaction and attachment with the developing fetus. ${ }^{(10)} M F A$ is thought to be associated with the woman's income. Financial inadequacies may cause the woman to be so preoccupied with her depleted circumstances that she becomes unable to respond effectively to the developing relationship with the fetus ${ }^{(11)}$.

Psychological factors include: maternal identity, stress and anxiety. A pregnant woman reformulates and alters her existing feminine identity to either develop or emphasize her established maternal identity. As early as (1984) Riva Rubin had reported that the recognition of one's maternal identity and the attachment to the fetus - and the infant later on- is an active, intermittent and cumulative process during pregnancy. ${ }^{(12)}$ Dramatic changes during pregnancy usually lead to stress and anxiety. When the pregnant woman perceives her pregnancy demands exceeding her adaptive capacity, stress could be triggered. Such behavioral responses could either enhance or hinder MFA. Anxiety is always present during pregnancy. In early pregnancy, anxiety is usually triggered by the uncertainty about the existence of pregnancy and the ability to go through it safely. Then other sources are added such as her concern about fetal health and development, her fearful expectations about labor pain and her ability to path through it safely. In addition to her worry about the efficiency of childbirth setting, health care givers as well as the expected economic burdens. As expected, the pregnant woman's level of anxiety is believed to be strongly related to the establishment as well as level of MFA ${ }^{(13,14)}$

Social factors, specifically, the availability and strength of social support are thought to be related to MFA. During pregnancy social support can buffer the intensity of pregnancy related stress, hence enhances the woman's energy to invest in her emotional well-being as well as establishment and enhancing MFA ${ }^{(15)}$. Finally, it should be noted that knowledge about what may influence MFA plays a significant role in understanding what kind of care and support they need. Hence, pregnant woman with low attachment level could be directed to receive professional counseling.

\section{Materials \& Methods}

Research design: A descriptive research design was utilized in this study. Setting: This study was conducted at the outpatient clinic of antenatal unit at El Shatby Maternity Hospital. It receives clients from Alexandria as well as adjacent governorates namely: Elbehera, et al.

Subjects: according to Epi info 7 program sample size estimation program a convenience sample of 350 pregnant women out of 3600 (representing the average number of women attending the previously mentioned setting during the last three months prior to the study) were recruited in the study.

Inclusion criteria: women who have normal pregnancy, absence of any chronic disease, at $2^{\text {nd }}$ and $3^{\text {rd }}$ trimesters of pregnancy, willing to participate in the study was included in the study.

Tools: five were used to collect the necessary data:

Tool (1): Pregnant women basic data structured interview schedule:

This tool was developed by the researcher. It entailed the following three parts; first part: women sociodemographic characteristics(age, level of education, occupation, marital status, residence \& family type), second part : women's reproductive history (gravidity, parity, number of abortions, stillbirths, nature of previous pregnancies, labor and postpartum in addition to number, age and sex of living children), third part : women's history / nature of current pregnancy (whether it was planned or not, weeks of gestation, number of antenatal visit).

\section{Tool (II): Anxiety inventory:}

This tool was originally proposed and revised by Spielberger (1983) to measure the anxiety level ${ }^{(16)}$. The researcher adapted and translated it into Arabic language. It comprises 20 items; 10 negative and 10 positive. Each item was scored on a 4 point likert- format as follows (4) Almost always, (3) Often,(2) 
Sometimes, (1) Almost never. The scoring was reversed for the positive statements (1, 2, 5, 8, 10, 11, 15, 16, 19 and 20).The total score ranged from 20 to 80 . Subjects' anxiety level was ranked as follows: low anxiety $<35$, mild anxiety $35-<50$, moderate anxiety $50-<65 \&$ severe anxiety $\geq 65$.

Tool (III): Social support structured interview schedule:

This scale was adapted from two other scales (Irwin Sarason et al, 1983) and (Zimet et al, 1988), and translated into Arabic language by the researcher to measure the subjects' level of current social support ${ }^{(17,18)}$. It includes 12 items; each item was categorized according to a 3 point likert format with the following values: agree ( 3 points), neutral ( 2 points), disagree (1 point).The total score ranged between12-36. Subjects' perceived social support level was ranked as follows: weak social support $<20$, fair social support $20-<28 \&$ strong social support $\geq 28$.

\section{Tool (IV): Verbal maternal-fetal attachment (VMFA) structured interview schedule:}

This tool was adapted from two scales (Cranley, 1981) and (Muller et al, 1993) and translated into Arabic language by the researcher to measure the subjects' VMFA level ${ }^{(19,20)}$. It entails 28 items divided into 6 sections. Specifically: Differentiation of self from fetus (4items), Attributing characteristics to the coming baby (5items), Interaction with fetus (7items), Sprout of feeling (5items), Giving of self (4items) and Role taking (3items). Subjects' response to each item varied among a 4 point likert scale. Namely: never (1), sometimes (2), often (3) and always (4). Each subject's total score ranged between 28 and 112. Each Subject's VMFA level ranked as follows: not attached $<49$, poorly attached $49-<70$, moderately attached $70-<91$, highly attached $\geq$ 91.

\section{Tool (V): The Pictorial Representation of Attachment Measure (PRAM):}

This tool was adapted from (Van Bakel, et al 2009). It was translated into Arabic language by the researcher to assess the nonverbal maternal-fetal attachment ${ }^{(21)}$. Subjects were provided a white A4-size paper with a big circle in the center (diameter of $18.6 \mathrm{~cm}$ ). It represents her current life sphere. A yellow circle of $5 \mathrm{~cm}$ in the center of the big one representing the mother's self. Subjects' were asked to mark a cross representing her unborn child in her life sphere at the moment. The total score is the distance in centimeters, between the 'Baby' and the center of the 'Self' circle for all subjects. It could range from 0 to $9.30 \mathrm{~cm}$. A smaller distance indicates more feelings of attachment, and vice versa. Subjects' maternal fetal attachment level ranked as follows: Not attached $\geq 7 \mathrm{~cm}$, weakly attached $4.65 \mathrm{~cm}-<7 \mathrm{~cm}$, fairly attached $2.3 \mathrm{~cm}-<4.65 \mathrm{~cm}$, strongly attached $\leq 2.3$ $\mathrm{cm}$.

\section{Method}

The study was conducted according to the following steps:

1. An official letter from the Faculty of Nursing-University of Alexandria was directed to the responsible authorities of El Shatby Maternity Hospital to obtain permission to conduct the study and collect the necessary data.

2. Tool (I) was developed by the researcher based on extensive review of recent relevant literature. Tool (II), (III), (IV), (V) were adapted and translated into Arabic language.

3. Tools were tested for content validity by a jury of five experts in the field of obstetric and gynecologic nursing. The recommended modifications were done and the final form was finalized after proving valid.

4. Tools reliability was tested by cronbach's alpha test. Tool II was 0.829, Tool III, was 0.957, Tool IV reliability was tested for each subscale. Differentiation of self from fetus (4items) was 0.746, Attributing characteristics to the coming baby (5items) was 0.758 , Interaction with fetus (7items) was 0.779 , Sprout of feeling (5items) was 0.718 , Giving of self (4items) was 0.728 and Role taking (3items) was 0.704 . The results were statistically acceptable.

5. A pilot study was carried out on 35 pregnant women (excluded from the study subjects) from the previously mentioned settings to assure feasibility of the study, clarity and applicability of the tools and to identify obstacles that might interfere with the process of data collection. Tools were modified accordingly prior to data collection.

6. Each woman was individually interviewed. The duration of each interview ranged between 30-45 minutes. Three days per week (from 8:30 am to 1:30 pm) were specified for data collection over a period of four months, started from the beginning of June till the end of September 2015. An average of 6 to 10 interviews was performed per day.

7. The collected data was revised, categorized, coded, computerized, tabulated and analyzed using Statistical Package for Social Sciences (SPSS) version 16. The given graphs were constructed using Microsoft excel software version 2010. The following statistical measures were used:

A) Descriptive statistics: included frequency, percent and mean with standard deviation to describe the scale and categorical data.Analysis of categorical data: 
- $\quad$ The average of verbal and nonverbal MFA was calculated.

- Fisher's exact probability was calculated using Mont Carlo method and ${ }^{\mathrm{FET}} \mathrm{P}$ were used to explore relationships between variables.

- $\quad$ P value $\leq 0.05$ was considered statistically significant.

- $\quad$ Spearman's correlation coefficient (Rho).

Rho value (-) negative correlation, (+) positive correlation.

\section{B) Ethical considerations:}

For each recruited subject an informed oral consent was obtained after explaining the purpose of the study. In addition, her anonymity, privacy, freedom to withdraw from the study at any time and confidentiality of her data were all emphasized prior starting the interview.

\section{Results}

Table (1) shows the Socio-demographic characteristics of the study subjects. Slightly less than threefifths $(58.3 \%)$ of them were in their twenties, $31.7 \%$ of them were in their thirties and only $10 \%$ were teenagers. Similar percents $(31.7 \%)$ of them were either illiterate or holding secondary certificate. Almost all of them $(90.3 \%)$ were housewives and a few $(1.4 \%)$ were divorced. Considerable percents $(65.1 \% \& 62.6 \%)$ of them were dwelling urban areas within nuclear families, respectively.

Table (2) exhibits that only $28.0 \%$ of the study subjects were primigravida compared to $61.7 \%$ multigravida. Slightly more than two-fifths $(45.2 \%)$ of them were primipara. A close percents $(14.3 \%$ and $10.3 \%$ ) of them had a history of either one or $\geq 2$ abortions, respectively. Only $11.5 \%$ of them had a history of stillbirth, either once $(8.3 \%)$ or more $(3.2 \%)$. Slightly less than two-thirds $(63.1 \%)$ of them had two years or more pregnancy interval between the current pregnancy and the last delivery. About three-quarters $(75.9 \%)$ of them did deliver their last child through cesarean section.

Table (3) demonstrates that nearly three-quarters (74.0\%) of the study subjects had a wanted/ planned pregnancy. The majority $(91.1 \%)$ of them were in their third trimester of pregnancy. Approximately half (49.2\%) of them had male fetus and about one-third (37.4\%) had a female fetus. As much as $81.4 \%$ of them had initiated their ante-natal visits during the first trimester of pregnancy. Almost all (94.3\%) of them had attended four or more ante-natal visits at the time of data collection.

Figure (1) shows that approximately one-half (47.2\%) of the study subjects had a moderate anxiety level, compared to $29.1 \%$ who had mild anxiety level. Severe anxiety level was observed among only $19.1 \%$ of them.

Figure (2) denotes that the majority (86.3\%) of the study subjects had strong social support. Only $8.6 \%$ and $5.1 \%$ of them had either fair or weak social support, respectively.

Figure (3) shows that $81.5 \%$ of the study subjects had strong overall maternal-fetal attachment level, compared to $13.4 \%$ who were moderately attached. Only $3.4 \%$ and $1.7 \%$ of them were either weakly or not attached, respectively.

Table (4) portrays the relationship between study subject's socio-demographic characteristics and their overall maternal-fetal attachment level. Generally speaking, only age was statistically significantly negatively correlated with overall maternal-fetal attachment level $(P=0.015)$, (Rho $=-0.249)$. That is to say, with increased maternal age, level of overall maternal-fetal attachment decreased. Specifically, As much as $94.3 \%$ of the teenage participants were strongly attached, compared to only $72.1 \%$ of those who were in their thirties or more. The same table indicates no statistically significant correlation between the study subjects' other sociodemographic characteristics and their overall maternal-fetal attachment level.

Table (5) exhibits the relationship between study subject's reproductive history and their overall maternal-fetal attachment level. Only gravidity was statistically significantly negatively correlated with level of maternal fetal attachment $(\mathrm{P}=0.001)$, $(\mathrm{Rho}=-0.373)$. That is to say, with increased number of pregnancies, level of attachment decreased. Where almost all (94.9\%) primigravida women were strongly attached, compared to nearly three-fourths of either multigravida (76.8\%) or grand multigravida $(72.2 \%)$.

According to table (6) a statistically significant correlation is observed between the overall level of maternal fetal attachment and some history of current pregnancy. Namely: pregnancy planning $(\mathrm{P}=0.000)$, sex of fetus $(P=0.012)$, time of the first antenatal visit $(P=0.000)$, number of antenatal visits $(P=0.025)$. Specifically, more than four-fifths $(87.6 \%)$ of the subjects with planned pregnancies had a strong overall maternal-fetal attachment level, compared to only $63.7 \%$ of those with unplanned pregnancies. A statistically significant negative correlation $(\mathrm{Rho}=-0.212)$ is observed in relation to the time of first antenatal visit. Where $85.2 \%$ of those who initiated antenatal care during first trimester compared to only $66.7 \%$ of those who initiated it during second trimester were strongly attached. More than four-fifth $(82.5 \%)$ of those who attended a satisfactory number of antenatal visits ( $\geq 4$ visits) during the current pregnancies were strongly attached, compared to only $65.0 \%$ of those with unsatisfactory number of antenatal visits. 
Table (7) portrays no statistically significant correlation between subjects' overall Maternal-fetal attachment level and their anxiety level $(\mathrm{P}=0.385)$. The majority $(83.1 \%, 84.3 \%$ and $93.8 \%)$ of those who had strong overall maternal-fetal attachment level expressed a moderate, mild and low anxiety level, respectively. While only $70.1 \%$ of them expressed a severe anxiety level.

According to table (8) a statistically significant positive correlation was noticed between subjects' level of overall maternal-fetal attachment and their level of perceived social support $(P=0.001)$, $($ Rho $=0.220)$. Where the majority $(83.4 \%)$ of the subjects with strong social support were strongly attached with their fetuses compared to only $72.2 \%$ of those with weak social support.

\section{Discussion}

Transition to motherhood is both complex and challenging. It requires extensive physical, psychological and social efforts. This transition confirms the development of maternal identity. Maternal-fetal attachment (MFA) is an important component of maternal identity and plays an important role in the maternal and fetal well-being. ${ }^{(22)}$ In spite of the presence of consistent evidence about individual differences in the level of MFA, there is still a need to clarify its associated factors. Hence, this study aimed to identify the factors associated with MFA in El-Shatby Maternity Hospital. The discussion of the present study results will be presented under four main headings: demographic, reproductive, current pregnancy profile, psychological and social factors.

\section{Demographic factors}

The present study revealed a statistically significant negative correlation between MFA and mothers' age. That is to say, with increased maternal age MFA decreased. This result is in line with the findings of three other researches. First: Berryman JC et al (1996) ${ }^{(23)}$ who had assessed Pregnancy after 35 year and attachment to the fetus in United Kingdom. Their results showed that women aged 35 years or more had a significantly lower maternal-fetal attachment scores than younger ones. Second Ustunsoz A et al (2010) ${ }^{(24)}$, who had compared maternal-fetal attachment and paternal-fetal attachment among Turkish couples in Ankara, Turkey. They found out that maternal-fetal attachment decreases with increased age among their study participants. Third: Baghdari $\mathbf{N}$ et al (2016) ${ }^{(25)}$ who had examined the effects of pregnancy-adaptation training on maternalfetal attachment and adaptation in pregnant women with a history of baby loss in Iran. They reported an inverse association between their subjects' age and their maternal-fetal attachment level. This agreement could be explained by the fact that older mothers usually have children and multiple responsibilities in their lives. Where number of children ordinary increases with age, making the adaptation to a current pregnancy so difficult which could be a reason for the decreased maternal-fetal attachment level among mothers with higher ages.

Mothers' level of education was not correlated with MFA in the present study. Where MFA was almost equally evident among highly educated as well as low educated ones. This result was unexpected since education usually paves the way to more health information seeking and utilization. Also highly educated mothers are expected to have developed more adequate skills to foster their children's development. However, this result agrees with the findings of the Iranian study conducted by Abasi $\mathbf{E}$ et al (2012) ${ }^{(\mathbf{2 6})}$. Where they reported no significant correlation between MFA scores and their subjects education.

\section{Reproductive factors}

The current study revealed a statistically significant negative correlation between MFA and pregnant woman's gravidity. That is to say, with increased gravidity MFA level decreased. This finding is similar to the results of two other studies. First: Nichols MR et al(2007) ${ }^{(27)}$ who had conducted a study in USA titled "Primigravid and multigravid women: prenatal perspectives". They demonstrated that multigravida women have lower levels of maternal fetal attachment than the primigravidas. Second: an Egyptian study by Moussa $\mathbf{S}$ et al $\mathbf{( 2 0 1 2 )}^{(\mathbf{2 8})}$, who had conducted a study titled "Correlates of antenatal bonding". Where the results of these two studies had confirmed the present study same result. Such an agreement is kind of expected, since primigravida women have eagerness to assume a new role that had never been experienced before. Moreover, they are more preoccupied with thoughts and emotions about their pregnancy and the growing fetus. This would positively reflect on MFA level. ${ }^{(29)}$

MFA had no correlation with parity in the current study. This result is congruent with the findings of the previously mentioned United Kingdom study conducted by Berryman $\mathbf{J}$ et al (1996) ${ }^{(23)}$ Yet, this same finding disagrees with the findings of other five researches. First: Condon JT et al (1990) ${ }^{(29)}$ who had studied the influence of parity on the experience of pregnancy: a comparison of first- and second-time expectant couples, in South Australia. Second: Haedt A et al (2007) ${ }^{(30)}$ who had studied maternal attachment, depression, and body dissatisfaction in pregnant women in USA . Third: Sandbrook S $(\mathbf{2 0 0 9})^{(\mathbf{3 1})}$ who had conducted a study titled "Love or protection? Defining and measuring maternal-fetal attachment from the woman's perspective "in United Kingdom. In addition to the previously mentioned Turkish and Egyptian studies done by Ustunsoz A 
et al (2010) ${ }^{(24)}$ and Moussa $S$ et al (2012) ${ }^{(28)}$, respectively. They all reported the presence of a negative correlation between MFA level and parity, where multiparous women had significantly lower MFA levels compared to primiparous women.

This inconsistency between the results of those studies and the current study findings could be attributed to the difference between the used MFA scales in each study. Where in present study a modified version of three tools were used to determine subjects' MFA from different dimension (verbal and nonverbal). While the other contradicting studies had used only one maternal-fetal attachment scale (MFAS Cranley, 1981).

\section{Current Pregnancy profile:}

Current pregnancy profile was statistically significantly correlated with MFA level in the present study. It was specifically associated with whether the pregnancy planning/wantedness, weeks of gestation, sex of fetus, attendance of antenatal visits and presence of minor discomforts or complications. MFA level was stronger among mothers with planned/wanted pregnancies in the present study. This result is in accordance with the findings of other four studies. Namely, Deeds O et al (2008).$^{(32)}$ titled" Partner relationships during the transition to parenthood" in Portugal. The two previously mentioned Turkish and Iranian studies done by Ustunsoz A et al (2010) ${ }^{(24)}$, Abasi E et al (2012) ${ }^{(26)}$, respectively. In addition to Hurtado M. (2015) ${ }^{(33)}$ titled " A program to improve maternal-fetal attachment among Latina mothers: A grant proposal" in USA. They all agreed that unplanned / unwanted pregnancy is associated with lower level of MFA than the planned/wanted ones.

On the other hand, this same present study result disagrees with the findings of two other studies. Namely, Damato EG. (2004) ${ }^{(34)}$ who had assessed the predictors of prenatal attachment in mothers of twins in USA. In addition to the previously discussed American study done by Mercer RT et al. (1988) ${ }^{(35)}$. Both studies reported absence of any correlation between MFA level and readiness for pregnancy.

MFA was statistically significantly correlated with the sex of fetus. That is to say, the gender of the fetus through antenatal testing (ultrasound) was significantly correlated to subjects' attachment level. This result may be explained by the fact that the visualization of fetal details definitely helps the woman to form a separate identity for the fetus. Consequently, it may impact on mothers' conversations, planning, and wishful thinking for the future of her unburned fetus. This agrees with the findings of two other studies. Jamshidimanesh $\mathbf{M}$ et al (2013) $^{(36)}$ titled "Maternal-Fetal Attachment and its Associated Factors" in Tehran, Iran. He had concluded that knowing the sex of the fetus had positive association on MFA. Lahann RL et al (2008) ${ }^{(37)}$ titled "Examination of Maternal-fetal Attachment in Singleton and Twin Pregnancies" in USA. They found out that knowing the gender of the fetus was significantly positively correlated with MFA level.

\section{Psychological factors}

In pregnancy, mild anxiety motivates the pregnant women to respond to their environments and conscientiously engage in health-promoting behaviors. Anxiety level was not correlated with MFA in the present study. This result is incongruent with the findings of four other researches. First: Condon J. T et al (1997) $^{(38)}$ who had studied the correlates of antenatal attachment in pregnant women in Australia. Second: Hart $\mathbf{R}$ et al (2006) ${ }^{(39)}$, who had studied the impact of depression and anxiety on MFA among first-time, low obstetric risk mothers in Australia. Third: Schmidt EB et al (2009) ${ }^{(40)}$ who had conducted a study titled " Pregnant women's bonding and maternal-fetal attachment "in Brazil. Fourth: the previously mentioned Iranian study conducted by Abasi $\mathbf{E}$ et al (2012) ${ }^{(26)}$. They all reported a significant inverse correlation between anxiety level and the overall Maternal-Fetal Attachment. The contradiction between the present study result and those of the four aforementioned ones could be attributed to the fact that socio-demographic background of the present study participants is greatly different than that of the Iranian, Brazilian and Australian ones. Where the Egyptian culture is very supportive in pregnancy. Consequently, sources and level of anxiety are expected to be lower and MFA would be easier.

\section{Social factors:}

In the present study, strong MFA level was observed among mothers with strong social support. This finding is congruent with the results of three other studies. First: the previously mentioned Australian study conducted by Condon JT et al (1997) ${ }^{(38)}$, he found that increased levels of social support were significantly correlated with higher scores on MFA. Second: Hjelmstedt A (2006) ${ }^{(41)}$ who had performed a study titled "Psychological correlates of prenatal attachment in women who conceived after in vitro fertilization and women who conceived naturally" in Sweden. He had reported that mothers with higher social support are more likely to establish emotional attachment with their fetuses. Third: Facello DC et al (2008) ${ }^{(42)}$ who had conducted a study titled "Maternal-fetal Attachment: Associations Among Family Relationships, Maternal Health Practices, and Antenatal Attachment" in Virginia, USA. They concluded that social support was positively correlated with MFA. 
However, this same result is incongruent with the findings of another two studies. First: the previously mentioned American study conducted by Mercer RT(1988) ${ }^{(35)}$ who had found no appreciable correlation between perceived social support and MFA. Second: Koniak-Griffin D (1993) ${ }^{(43)}$ who had studied social support during adolescent pregnancy among three ethnic groups" in USA. He had reported no statistically significant correlation between social support and MFA. This inconsistency between the results of these two American studies and the current study findings could be attributed to the nature of social support in the two completely different Egyptian and American cultures. Where in Egypt pregnancy is usually a family event where all family members are involved, such as the maternal and paternal, grandparents unlike the American societies. In addition to the difference between the social support scales used in each study. Where in present study had used a modified version that was adapted from two scales (Irwin Sarason et.al, 1983) and (Zimet, 1988), while the former American studies used Nor beck's Social Support Questionnaire (NSSQ) and the later used the Barrera Inventory of Socially Supportive Behaviours.

\section{Conclusion}

\section{Conclusion and Recommendations}

Based on the findings of the present study, maternal-fetal attachment level was associated with some predictive factors. Namely, maternal age, gravidity, planned /desired pregnancies, identification of the fetal sex, time of the initial antenatal visit, number of antenatal visits and presence of social support.

\section{Recommendations}

Based on the findings of the present study, the following recommendations are suggested:

1. The issue of maternal-fetal attachment is recommended to be included within maternity nursing curricula at different nursing educational institutions.

2. Antenatal maternity nurses better include within their clients' assessment, the assessment of the level of maternal-fetal attachment.

3. According to their assessment, they are advised to reinforce factors that enhance maternal-fetal attachment.

\section{Future studies:}

1. Replication of the present study among different Egyptian cultures such as Upper Egypt or rural areas.

2. Replication of the same study on high-risk pregnant women.

Table( 1): Number and percent distribution of the study subjects according to their socio-demographic characteristics

\begin{tabular}{|c|c|c|}
\hline Socio-demographic characteristics & Number (350) & Percent $(\%)$ \\
\hline \multirow[t]{2}{*}{$\begin{array}{l}-\quad \text { Age: } \\
-\quad<20 \\
-\quad 20-<30 \\
-\quad 230\end{array}$} & $\begin{array}{c}35 \\
204 \\
111\end{array}$ & $\begin{array}{l}10.0 \\
58.3 \\
31.7\end{array}$ \\
\hline & \multicolumn{2}{|c|}{ Mean $\pm \mathrm{SD}=26.77 \pm 5.938$} \\
\hline $\begin{array}{ll}- & \text { Level of education: } \\
- & \text { Illiterate } \\
- & \text { Primary level } \\
- & \text { Secondary level } \\
- & \text { University or higher level }\end{array}$ & $\begin{array}{r}111 \\
78 \\
111 \\
50\end{array}$ & $\begin{array}{l}31.7 \\
22.3 \\
31.7 \\
14.3\end{array}$ \\
\hline $\begin{array}{ll} & \text { Occupation: } \\
- & \text { Housewives } \\
- & \text { Worker } \\
- & \text { Employer }\end{array}$ & $\begin{array}{c}316 \\
8 \\
26\end{array}$ & $\begin{array}{r}90.3 \\
2.3 \\
7.4\end{array}$ \\
\hline $\begin{array}{ll} & \text { Marital status : } \\
- & \text { Married } \\
- & \text { Divorced } \\
\end{array}$ & $\begin{array}{l}345 \\
5 \\
\end{array}$ & $\begin{array}{c}98.6 \\
1.4 \\
\end{array}$ \\
\hline $\begin{array}{ll}- & \text { Residence: } \\
- & \text { Urban } \\
- & \text { Rural } \\
\end{array}$ & $\begin{array}{l}228 \\
122 \\
\end{array}$ & $\begin{array}{l}65.1 \\
34.9\end{array}$ \\
\hline $\begin{array}{ll}- & \text { Family type: } \\
- & \text { Nuclear } \\
- & \text { Extended }\end{array}$ & $\begin{array}{l}219 \\
131\end{array}$ & $\begin{array}{l}62.6 \\
37.4\end{array}$ \\
\hline
\end{tabular}


Table (2): Number and percent distribution of the study subjects according to their reproductive history

\begin{tabular}{|c|c|c|}
\hline Reproductive history & Number & Percent $(\%)$ \\
\hline \multirow[t]{2}{*}{$\begin{array}{ll}- & \text { Gravidity }(\mathbf{n}=\mathbf{3 5 0}): \\
- & \text { Primigravida } \\
- & \text { Multigravida } \\
- & \text { Grand multigravida }(\geq 5)\end{array}$} & $\begin{array}{r}98 \\
216 \\
36 \\
\end{array}$ & $\begin{array}{l}28.0 \\
61.7 \\
10.3\end{array}$ \\
\hline & \multicolumn{2}{|c|}{ Mean $\pm \mathrm{SD}=2.62 \pm 1.574$} \\
\hline $\begin{array}{ll}- & \text { Parity }(\mathbf{n}=\mathbf{2 4 1}): \\
- & \text { One } \\
- & \text { Two } \\
- & \geq \text { Three }\end{array}$ & $\begin{array}{c}109 \\
77 \\
55\end{array}$ & $\begin{array}{l}45.2 \\
32.0 \\
22.8\end{array}$ \\
\hline $\begin{array}{ll}- & \text { Number of abortions }(\mathbf{n}=\mathbf{2 5 2}) \\
- & \text { No } \\
- & \text { Once } \\
- & \geq \text { twice }\end{array}$ & $\begin{array}{l}190 \\
36 \\
26 \\
\end{array}$ & $\begin{array}{l}75.4 \\
14.3 \\
10.3 \\
\end{array}$ \\
\hline $\begin{array}{ll} & \text { Number of stillbirths }(\mathbf{n}=\mathbf{2 5 2}) \\
- & \text { No } \\
- & \text { Once } \\
- & \geq \text { twice }\end{array}$ & $\begin{array}{c}223 \\
21 \\
8 \\
\end{array}$ & $\begin{array}{r}88.5 \\
8.3 \\
3.2 \\
\end{array}$ \\
\hline $\begin{array}{ll}- & \text { Number of living children: }(\mathbf{n}=\mathbf{2 3 0}) \\
- & \text { One child } \\
- & \text { Two children } \\
- & \text { Three children or more } \\
\end{array}$ & $\begin{array}{c}104 \\
79 \\
47\end{array}$ & $\begin{array}{l}45.3 \\
34.3 \\
20.4\end{array}$ \\
\hline $\begin{array}{ll}- & \text { Sex of living children: }(\mathbf{n}=\mathbf{2 3 0}) \\
- & \text { Males } \\
- & \text { Females } \\
- & \text { Both } \\
\end{array}$ & $\begin{array}{l}74 \\
73 \\
83 \\
\end{array}$ & $\begin{array}{l}32.2 \\
31.7 \\
36.1\end{array}$ \\
\hline $\begin{array}{l}\text { Space between the current pregnancy and last } \operatorname{delivery}(\mathbf{n}=\mathbf{2 4 1}): \\
-\quad<2 \text { years } \\
-\quad \geq 2 \text { years }\end{array}$ & $\begin{array}{c}89 \\
152 \\
\end{array}$ & $\begin{array}{l}36.9 \\
63.1 \\
\end{array}$ \\
\hline
\end{tabular}

Table (3): Number and percent distribution of the study subjects according to their profile of current pregnancy

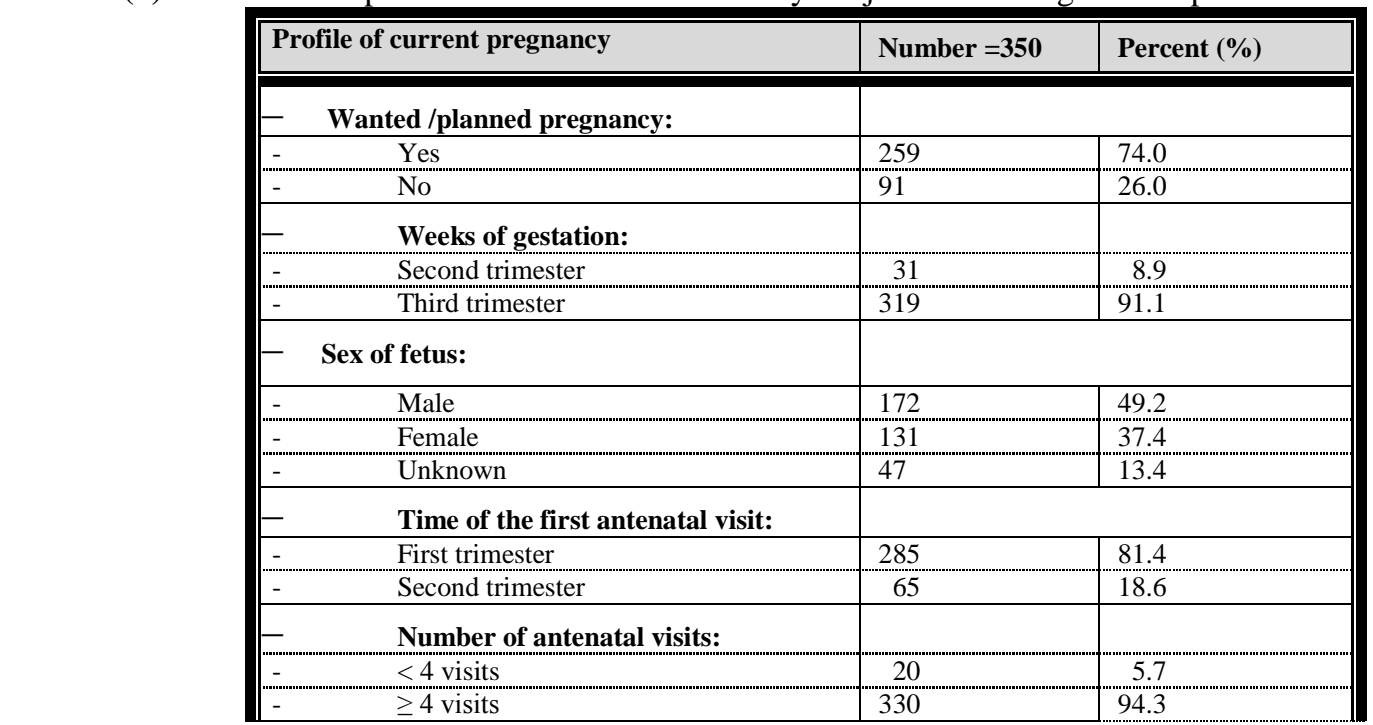

\# Total is not exclusive 


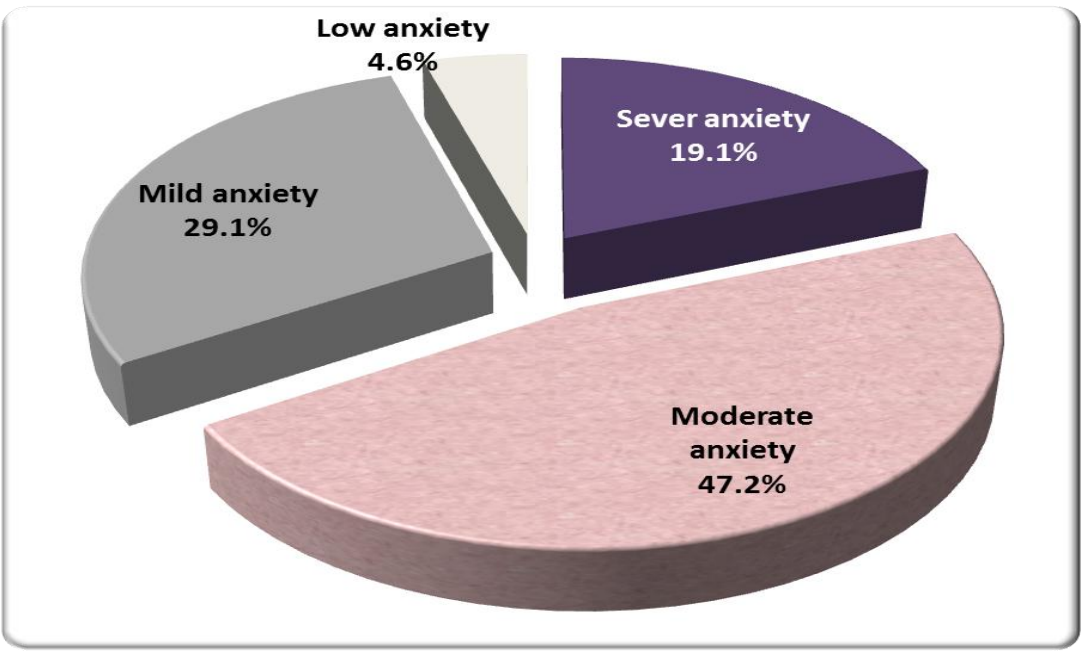

Figure (1): Percent distribution of the study subjects according to their anxiety level

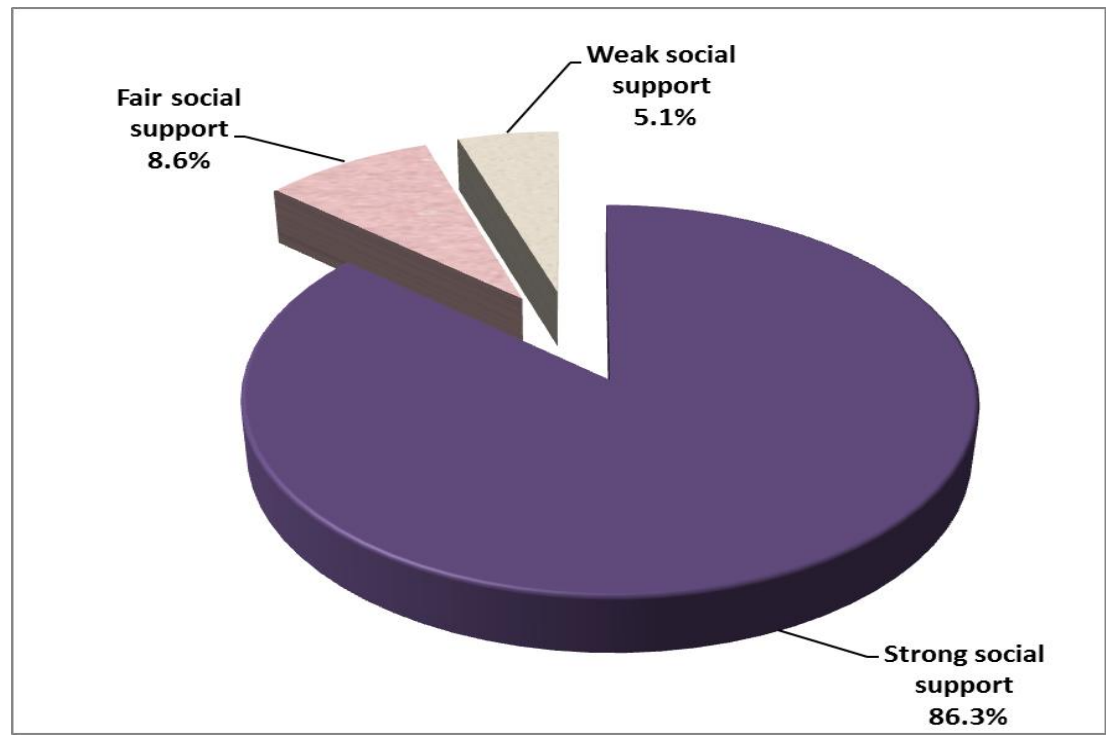

Figure (2): Percent distribution of the study subjects according to their social support level

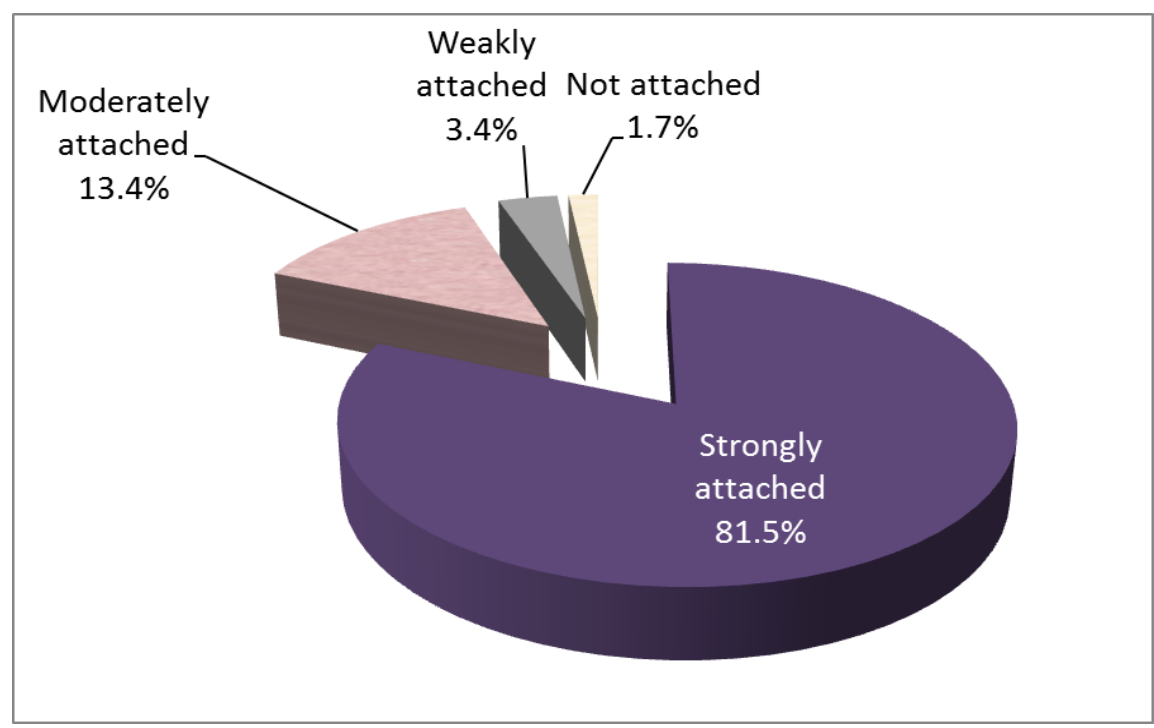

Figure (3): Distribution of study subjects according to their overall maternal-fetal attachment level (verbal and nonverbal) 
Table (4): Relationship between study subject's socio-demographic characteristics and their overall maternalfetal attachment level

\begin{tabular}{|c|c|c|c|c|c|c|c|c|c|}
\hline \multirow{3}{*}{$\begin{array}{l}\text { Socio-demographic } \\
\text { Characteristics }\end{array}$} & \multicolumn{8}{|c|}{ Overall Maternal-fetal attachment level $(n=350)$} & \multirow{3}{*}{$\begin{array}{l}\text { Fisher's exact } \\
\text { test }\end{array}$} \\
\hline & \multicolumn{2}{|c|}{ Strongly attached } & \multicolumn{2}{|c|}{$\begin{array}{l}\text { Moderately } \\
\text { attached }\end{array}$} & \multicolumn{2}{|c|}{$\begin{array}{l}\text { Weakly } \\
\text { attached }\end{array}$} & \multicolumn{2}{|c|}{ Not attached } & \\
\hline & no & $\%$ & no & $\%$ & no & $\%$ & no & $\%$ & \\
\hline \multicolumn{9}{|l|}{ - Age: } & \multirow{2}{*}{$0.015^{*}$} \\
\hline$<20$ & 33 & 94.3 & 2 & 5.7 & 0 & 0.0 & 0 & 0.0 & \\
\hline \multicolumn{9}{|l|}{ - Level of education: } & \multirow{5}{*}{0.364} \\
\hline Illiterate & 87 & 78.4 & 16 & 14.4 & 7 & 6.3 & 1 & 0.9 & \\
\hline Primary & 67 & 85.9 & 9 & 11.5 & 0 & 0.0 & 2 & 2.6 & \\
\hline Secondary & 92 & 82.9 & 15 & 13.5 & 3 & 2.7 & 1 & 0.9 & \\
\hline University & 39 & 78.0 & 7 & 14.0 & 2 & 4.0 & 2 & 4.0 & \\
\hline \multicolumn{9}{|l|}{ - Marital status : } & \multirow{3}{*}{0.251} \\
\hline - $\quad$ Married & 281 & 81.5 & 47 & 13.6 & 11 & 3.2 & 6 & 1.7 & \\
\hline Divorced & 4 & 80.0 & 0 & 0.0 & 1 & 20.0 & 0 & 0.0 & \\
\hline \multicolumn{9}{|l|}{ - Residence: } & \multirow{3}{*}{0.913} \\
\hline - $\quad$ Urban & 183 & 80.3 & 32 & 14.0 & 9 & 3.9 & 4 & 1.8 & \\
\hline 'mural & 102 & 83.6 & 15 & 12.3 & 3 & 2.5 & 2 & 1.6 & \\
\hline \multicolumn{9}{|l|}{-Type of family: } & \multirow{3}{*}{0.490} \\
\hline - $\quad$ Nuclear & 178 & 81.3 & 31 & 14.2 & 8 & 3.7 & 2 & 0.9 & \\
\hline "Expended & 107 & 81.6 & 16 & 12.2 & 4 & 3.1 & 4 & 3.1 & \\
\hline
\end{tabular}

${ }^{\text {FET }} \mathrm{P}$ : Fisher Exact test

*: Significant at $\mathrm{P} \leq 0.05$

Table (5): Relationship between study subject's reproductive history and their overall maternal-fetal attachment level

\begin{tabular}{|c|c|c|c|c|c|c|c|c|c|}
\hline \multirow{3}{*}{ Reproductive history } & \multicolumn{8}{|c|}{ Overall Maternal-fetal attachment level $(n=350)$} & \multirow{3}{*}{$\begin{array}{l}\text { Fisher's } \\
\text { exact test }\end{array}$} \\
\hline & \multicolumn{2}{|c|}{$\begin{array}{l}\text { Strongly } \\
\text { attached }\end{array}$} & \multicolumn{2}{|c|}{$\begin{array}{l}\text { Moderately } \\
\text { attached }\end{array}$} & \multicolumn{2}{|c|}{$\begin{array}{l}\text { Weakly } \\
\text { attached }\end{array}$} & \multicolumn{2}{|c|}{$\begin{array}{c}\text { Not } \\
\text { attached }\end{array}$} & \\
\hline & no & $\%$ & no & $\%$ & no & $\%$ & No & $\%$ & \\
\hline - Gravidity: & 93 & 94.9 & 5 & 5.1 & 0 & 0.0 & 0 & 0.0 & \multirow{3}{*}{$0.001^{8}$} \\
\hline - Mültigravida & 166 & 76.8 & $36 \cdots$ & $16 \%$ & 9 & 42 & 5 & 2.3 & \\
\hline - Grandmultigravida & 26 & 72.2 & 6 & $16 \%$ & 3 & 8.3 & r... & 2.8 & \\
\hline \multirow{3}{*}{$\begin{array}{l}\text { Parity(n=241): } \\
\text { - One } \\
\text { - Two }\end{array}$} & 86 & 78.9 & 17 & 15.6 & 4 & 3.7 & 2 & 1.8 & \multirow{3}{*}{0.251} \\
\hline & 58 & 75.3. & 16 & 20.8 & 3 & 3.9 & 0 & 0.0 & \\
\hline & 38 & $69.1 \%$ & "و & 16.3 & $5 \cdots$ & 9.1 & 3 & $5.5 \cdots$ & \\
\hline \multirow{2}{*}{$\begin{array}{l}\text { - Number of abortion }(n=252) \\
- \text { No }\end{array}$} & & & & & & & & & \multirow{4}{*}{0.379} \\
\hline & 147 & 77.4 & 30 & 15.8 & 9 & 4.7 & 4 & 2.1 & \\
\hline$-1-$ Once - - - - - - - - - - - - & $26 \cdots$ & $72: 3 \cdots$ & y. & ry.4. & $3 \cdots$ & 8.3 & $\%$ & $0.0 \cdots$ & \\
\hline$-\geq 2$ & 19 & 73.1 & 5 & 19.2 & $\sigma^{\prime \cdots}$ & 0.0 & 2 & $7: y$ & \\
\hline \multirow{2}{*}{$\begin{array}{c}\text { - Number of stillbirth }(n=252) \\
- \text { No }\end{array}$} & & & & & & & & & \multirow{4}{*}{0.781} \\
\hline & 169 & 75.8 & 37 & 16.6 & 11 & 4.9 & 6 & 2.7 & \\
\hline -Once & 15 & 714 & 5 & 23.8 & $1 \cdots$ & 4.8 & $\%$ & $0.0 \cdots$ & \\
\hline$-\geq 2$ & 8 & 100.0 & $\sigma$ & 0.0 & $\%$ & $0.0 \%$ & $\%$ & 0.0 & \\
\hline \multirow{2}{*}{$\begin{array}{l}\text { Number of living children: }((n=230) \\
\text { - One child }\end{array}$} & 80 & 76.9 & 18 & 17.3 & 3 & 2.9 & 3 & 2.9 & \multirow{4}{*}{0.118} \\
\hline & & & & & & & & & \\
\hline -Two children & 61 & 77.2 & 14 & $17 \%$ & 4 & 5.1 & $\%$ & $0.0 \cdots$ & \\
\hline - Three children or more & 29 & $61 \%$ & 10\% & 21.3 & 5 & 10.6 & 3 & 6.4 & \\
\hline \multirow{2}{*}{$\begin{array}{l}\text { Sex of living children( } n=230): \\
\text { - Males }\end{array}$} & 49 & 66.1 & 17 & 23.0 & 7 & 9.5 & 1 & 1.4 & \multirow{4}{*}{0.062} \\
\hline & & & & & & & & & \\
\hline - Females & 59 & 80.8 & 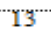 & r.s.8. & 0 & 0.0 & 1 & 14 & \\
\hline - Males and females & 63 & 75.9 & 12 & 14.5 & 5 & 6.0 & 3 & 3.6 & \\
\hline \multirow{2}{*}{$\begin{array}{l}\text { - Space between the current pregnancy } \\
\text { and last delivery: }(\mathrm{n}=241)\end{array}$} & & & & & & & & & \multirow[t]{3}{*}{0.182} \\
\hline & 72 & 80.9 & 12 & 13.5 & 2 & 2.2 & 3 & 3.4 & \\
\hline$-\geq 2$ years & rYo & 72.4 & 30 & 19.7 & Yo & 6.6 & 2 & 1.3 & \\
\hline
\end{tabular}

${ }^{\text {FET }} \mathrm{P}$ : Fisher Exact test

*: Significant at $\mathrm{P} \leq 0.05$ 
Table( 6): Relationship between study subject's profile of current pregnancy and their overall maternal-fetal attachment level

\begin{tabular}{|c|c|c|c|c|c|c|c|c|c|}
\hline \multirow[t]{3}{*}{ Profile of current pregnancy } & \multicolumn{8}{|c|}{ Overall Maternal-fetal attachment level $(n=350)$} & \multirow{3}{*}{$\begin{array}{c}\text { Fisher's } \\
\text { exact } \\
\text { test }\end{array}$} \\
\hline & \multicolumn{2}{|c|}{$\begin{array}{l}\text { Strongly } \\
\text { attached }\end{array}$} & \multicolumn{2}{|c|}{$\begin{array}{c}\text { Moderately } \\
\text { attached }\end{array}$} & \multicolumn{2}{|c|}{$\begin{array}{c}\text { Weakly } \\
\text { attached }\end{array}$} & \multicolumn{2}{|c|}{ Not attached } & \\
\hline & no & $\%$ & No & $\%$ & no & $\%$ & no & $\%$ & \\
\hline $\begin{array}{l}\text { - Wanted /planned pregnancy: } \\
\text { - Yes }\end{array}$ & 227 & 87.6 & 23 & 8.9 & 8 & 3.1 & 1 & 0.4 & \multirow[t]{2}{*}{$0.000 *$} \\
\hline$-\mathrm{No}$ & 58 & 63.7 & 24 & 26.4 & 4 & 4.4 & 5 & 5.5 & \\
\hline \multirow{2}{*}{$\begin{array}{c}\text { - Weeks of gestation: } \\
-\quad \text { Second trimester }\end{array}$} & & & & & & & & & \\
\hline & 23 & 74.2 & 5 & 16.1 & 2 & 6.5 & 1 & 3.2 & \multirow[t]{2}{*}{0.300} \\
\hline - Third trimester & 262 & 82.1 & 42 & 13.2 & 10 & 3.1 & 5 & 1.6 & \\
\hline $\begin{array}{c}\text { - Sex of fetus: } \\
\text { - Male }\end{array}$ & 147 & 85.5 & 14 & 8.1 & 8 & 4.7 & 3 & 1.7 & \multirow[t]{3}{*}{$0.021 *$} \\
\hline - Female & 105 & 80.1 & 23 & 17.6 & 2 & 1.5 & 1 & 0.8 & \\
\hline - Unknown & 33 & 70.1 & 10 & 21.3 & 2 & 4.3 & 2 & 4.3 & \\
\hline \multirow{3}{*}{$\begin{array}{l}\text { - Time of the first antenatal visit: } \\
\text { - First trimester } \\
\text { - Second trimester }\end{array}$} & & & & & & & & & \\
\hline & 243 & 85.2 & 33 & 11.6 & 7 & 2.5 & 2 & 0.7 & \multirow[t]{2}{*}{$0.000 *$} \\
\hline & 42 & 64.6 & 14 & 21.5 & 5 & 7.7 & 4 & 6.2 & \\
\hline \multirow{3}{*}{$\begin{array}{l}\text { - Number of antenatal visits: } \\
\text { - Less than } 4 \text { visits } \\
- \text { More than } 4 \text { visits }\end{array}$} & & & & & & & & & \multirow{3}{*}{$0.025^{*}$} \\
\hline & 13 & 65.0 & 3 & 15.0 & 3 & 15.0 & 1 & 5.0 & \\
\hline & 272 & 82.5 & 44 & 13.3 & 9 & 2.7 & 5 & 1.5 & \\
\hline
\end{tabular}

FET P: Fisher Exact test

*: Significant at $\mathrm{P} \leq 0.05$

Table (7): Relationship between study subject's anxiety level and their overall maternal-fetal attachment level

\begin{tabular}{|c|c|c|c|c|c|c|c|c|c|}
\hline \multirow[t]{3}{*}{ Anxiety level } & \multicolumn{8}{|c|}{ Overall Maternal-fetal attachment level $(n=350)$} & \multirow{3}{*}{$\begin{array}{l}\text { Fisher's } \\
\text { exact test }\end{array}$} \\
\hline & \multicolumn{2}{|c|}{$\begin{array}{l}\text { Strongly } \\
\text { attached }\end{array}$} & \multicolumn{2}{|c|}{$\begin{array}{c}\text { Moderately } \\
\text { attached }\end{array}$} & \multicolumn{2}{|c|}{$\begin{array}{l}\text { Weakly } \\
\text { attached }\end{array}$} & \multicolumn{2}{|c|}{ Not attached } & \\
\hline & No & $\%$ & no & $\%$ & No & $\%$ & no & $\%$ & \\
\hline - Severe anxiety & 47 & 70.1 & 13 & 19.4 & 4 & 6.0 & 3 & 4.5 & 0.385 \\
\hline - Moderate anxiety & 137 & 83.1 & 20 & 12.1 & 6 & 3.6 & 2 & 1.2 & \\
\hline - Mild anxiety & 86 & 84.3 & 13 & 12.7 & 2 & 2.0 & 1 & 1.0 & \\
\hline - Low anxiety & 15 & 93.8 & 1 & 6.2 & 0 & 0.0 & 0 & 0.0 & \\
\hline
\end{tabular}

${ }^{\text {FET }}$ P: Fisher Exact test $\quad$ *: Significant at $\mathrm{P} \leq 0.05$

Table (8): Relationship between study subject's social support level and their overall maternal-fetal attachment level

\begin{tabular}{|c|c|c|c|c|c|c|c|c|c|}
\hline \multirow[t]{3}{*}{ Social support } & \multicolumn{8}{|c|}{ Overall maternal-fetal attachment level $(n=350)$} & \multirow{3}{*}{$\begin{array}{l}\text { Fisher's } \\
\text { exact test }\end{array}$} \\
\hline & \multicolumn{2}{|c|}{ Strongly attached } & \multicolumn{2}{|c|}{ Moderately attached } & \multicolumn{2}{|c|}{ Weakly attached } & \multicolumn{2}{|c|}{ Not attached } & \\
\hline & No & $\%$ & no & $\%$ & no & $\%$ & no & $\%$ & \\
\hline - $\quad$ Strong social support & 252 & 83.4 & 41 & 13.6 & 6 & 2.0 & 3 & 1.0 & $0.001 *$ \\
\hline - $\quad$ Fair social support & 20 & 66.6 & 5 & 16.7 & 3 & 10.0 & 2 & 6.7 & \\
\hline - $\quad$ Week social support & 13 & 72.1 & 1 & 5.6 & 3 & 16.7 & 1 & 5.6 & \\
\hline
\end{tabular}

${ }^{\text {FET }} \mathrm{P}$ : Fisher Exact test \&P for $\mathrm{F}_{\mathrm{ET}}$ was calculated using Mont Carlo method

*: Significant at $\mathrm{P} \leq 0.05$

\section{References}

[1]. Peters TW, Wilson L. The Attachment Pregnancy: The Ultimate Guide to Bonding with Your Baby: Adams Media Corporation. 2014; 22-4. Available at URL:www.amazon.com/The-Greatest-Pregnancy-Ever-MotherBaby/dp/ 06155 $78985 /$ ref=pd_rhf_se_p_img_1\#reader_B00795VRME. Retrieved on: 20 May 2016.

[2]. Sandbrook SP, Adamson-Macedo EN. Maternal-Fetal Attachment: Searching for A new Definition. Neuro Endocrinol Lett. 2005;25:169-82.

[3]. Rubin R. Maternal Tasks in Pregnancy. Maternal-Child Nursing Journal. 1985;4(3):143-53.

[4]. Mercer RT. Becoming A mother versus Maternal Role Attainment. Journal of Nursing Scholarship. 2004;36:226-32.

[5]. Brandon A, Pitts S, Denton W, Stringer C, Evans H. A history of The Theory of Prenatal Attachment. Journal of Prenatal \& Perinatal Psychology and Health. 2009;23(4):201-22.

[6]. Malekpour M. Effects of Attachment on Early and Later Development. The British Journal of Developmental Disabilities. 2007;2(53): 81-95.

[7]. Ross E. Maternal Fetal Attachment and Engagement with Antenatal Advice. British Journal of Midwifery. 2012;20(8):566-75. 
[8]. Oppenheim D, Koren-Karie N, Sagi-Schwartz A. Emotion Dialogues between Mothers and Children at 4.5 and 7.5 Years: Relations with Children's Attachment at 1 Year. Child Development. 2007;78:38-52.

[9]. Schore AN. Back to Basics: Attachment, Affect Regulation and The Developing Right-brain: Linking Developmental Neuroscience. Pediatr Rev. 2005;26(6):204-17.

[10]. Cannella BL. Maternal-Fetal Attachment: An integrative Review. Journal of Advanced Nursing. 2005;50(1):60-8.

[11]. Solomon J, George C, Cassidy J, Shaver P. The caregiving System: A behavioral Systems Approach to Parenting. Handbook of Attachment: Theory, Research, and Clinical Applications, 2nd ed. New York: Guilford Press. 2008; 69-75.

[12]. Rubin R. Maternal identity and The maternal Experience. New York: Springer. 1984; 12-13.

[13]. Cunningham F, Bloom S, Hauth J, Rouse D, Spong C. Williams Obstetrics. 23rd ed. New York: McGraw-Hill Publication, 2010; 107-129.

[14]. Kessler RC, Petukhova M, Sampson N A, Zaslavsky AM, \& Wittchen HU. Twelve-Month and Lifetime Prevalence and Lifetime Morbid Risk of Anxiety and Mood Disorders in the United States. International Journal of Methods in Psychiatric Research. 2012;21(3):169-84.

[15]. Reis HT, Rusbult CE. Close Relationships: Key Readings: Psychology Press, 2004;12-22.

[16]. Spielberger CD. Assessment of State and Trait Anxiety: Conceptual and Methodological issues. Southern Psychologist. 1985;2(4): 6-16.

[17]. Sarason I, Levine H, Basham R, Sarason B. Social Support Questionnaire. Available at:URL.http: //web.psych.washington.edu/ research/ sarason/ files/ SocialSupportQuestionnaire. pdf . Retrieved on: 2 December 2014.

[18]. Zimet G, Dahlem N. The Multidimensional Scale of Perceived Social Support. Journal of Personality Assessment. 1988;52(1):3041.

[19]. Cranley MS. Development of A tool for The measurement of Maternal Attachment during Pregnancy. Nursing Research. 1981;30:281-4.

[20]. Muller MR, Mercer RT. Development of The Prenatal Attachment Inventory. Western Journal of Nursing Research. 1993;15:199215 .

[21]. Van Bakel HJ, Vreeswijk CM, \& Maas AJ. Verbal and Pictorial Representations of The antenatal Mother-Foetus Relationship. Journal of Reproductive and Infant Psychology. 2009;27(3):323.

[22]. Alhusen JL. A literature Update on Maternal-Fetal Attachment. Journal of Obstetric Gynecology Neonatal Nursing. 2008;37(3):315-28.

[23]. Berryman J, Windridge KC. Pregnancy after 35 and attachment to the fetus. Journal of Reproductive and Infant Psychology. 1996;14:133-43.

[24]. Ustunsoz A, Guvenc G, Akyuz A, Oflaz F. Comparison of Maternal-and Paternal-Fetal Attachment in Turkish Couples. Midwifery. 2010;26(2): 1-9.

[25]. Baghdari N, Sadeghi E, Kheirkhah M,Azmoude E. The Effects of Pregnancy-Adaptation Training on Maternal-Fetal Attachment and Adaptation in Pregnant Women with A history of Baby Loss. Nurs Midwifery Stud. (InPress). 2016;5-8.

[26]. Abasi E, Tahmasebi H, Zafari M, Takami G. Assessment of Effective Factors of Maternal-Fetal Attachment in Pregnant Women. Life Science Journal. 2012;9(1):68-75.

[27]. Nichols MR, Roux GM, Harris NR. Primigravid and Multigravid Women: Prenatal Perspectives. Journal of Perinatal Education. 2007;16(2):21-32.

[28]. Moussa S, Refaat O, Emad M, Khoweiled A, Goueli T, Ezzat M. Correlates of Antenatal Bonding (An Egyptian Study). 2012; 12634.

[29]. Condon JT, Esuvaranathan V. The influence of Parity on The experience of Pregnancy: A comparison of First- and Second-Time Expectant Couples. The British Journal of Medical Psychology.1990;63:369-77.

[30]. Haedt A, Keel P. Maternal Attachment, Depression and Body Dissatisfaction in Pregnant Women. Journal of Reproductive and Infant Psychology. 2007;25(4):285-95.

[31]. Sandbrook S. Love or Protection? Defining and Measuring Maternal-Fetal Attachment from The woman's Perspective: University of Wolverhampton. 2009;130-40.

[32]. Deeds O, Ascencio A, Figueiredo B, Field T, Diego M, Hernandez- Reif M. Partner Relationships during The Transition to Parenthood. Journal of Reproductive and Infant Psychology. 2008;26(2):99-107.

[33]. Hurtado M. A program to Improve Maternal-Fetal Attachment among Latina Mothers: A grant proposal: California State University, Long Beach. 2015; 67-80.

[34]. Damato EG. Predictors of Prenatal Attachment in Mothers of Twins. Journal of Obstetric, Gynecologic and Neonatal Nursing. 2004;33(4):436-45.

[35]. Mercer RT, Ferketich S, May K, DeJoseph J, Sollid D. Further Exploration of Maternal and Paternal- Fetal Attachment. Res Nurs Health. 1988;11(2):83-95.

[36]. Jamshidimanesh M, Astaraki L, Behboodi Moghadam Z, Taghizadeh Z \& Haghani H. Maternal-Fetal Attachment and its Associated Factors. Hayat. 2013;18(5):33-45.

[37]. Lahann RL. An Examination of Maternal-fetal Attachment in Singleton and Twin Pregnancies.USA: Capella University. 2008;1822.

[38]. Condon J. T\& Corkindale C. The correlates of Antenatal Attachment in Pregnant Women. British Journal of Medical Psychology 1997;70:359-72.

[39]. Hart R, McMahon CA. Mood State and Psychological Adjustment to Pregnancy. Archives of Women's Mental Health. 2006;9(6):329-37. PubMed PMID: 16830068. Epub 2006/07/11. eng.

[40]. Schmidt EB, Argimon DL. Pregnant Women's Bonding and Maternal-fetal Attachment Paidéia (Ribeirão Preto). 2009;19:211-20.

[41]. Hjelmstedt A, Widstrom AM, Collins A. Psychological Correlates of Prenatal Attachment in Women Who Conceived after In vitro Fertilization and Women Who Conceived Naturally. Birth (Berkeley, Calif). 2006;33(4):303-10. PubMed PMID: 17150069. Epub 2006/12/08. eng.

[42]. Facello DC, University WV. Maternal-fetal Attachment: Associations Among Family Relationships, Maternal Health Practices, and Antenatal Attachment: West Virginia University. 2008;53-64.

[43]. Koniak-Griffin D, Lominska S, Brecht ML. Social Support during Adolescent Pregnancy:A comparison of Three Ethnic Groups. Journal of Adolescence. 1993;16(1):43-56. PubMed PMID: 8496468. Epub 1993/03/01. eng 